\title{
PENGARUH TUMPANGSARI SELADA DAN SAWI TERHADAP PERTUMBUHAN DAN PRODUKSI DUA KULTIVAR GLADIOL (Gladiolus hybridus L.)
}

\author{
Dewansyah Sabtaki, Tri Dewi Andalasari \& Sri Ramadiana \\ Jurusan Agroteknologi, Fakultas Pertanian Universitas Lampung \\ Jl.Prof. Soemantri Brodjonegoro, No.1 Bandar Lampung 35145 \\ E-mail:dewansabtaki@yahoo.com
}

\begin{abstract}
ABSTRAK
Penelitian ini bertujuan untuk: (1) mengetahui pengaruh jenis tumpangsari pada pertumbuhan dan produksi dua kultivar gladiol, (2) mengetahui respon masing-masing kultivar terhadap jenis tumpangsari, (3) mengetahui jenis kombinasi tumpangsari yang berpengaruh terhadap masing-masing kultivar gladiol. Penelitian ini disusun dengan menggunakan rancangan perlakuan faktorial 2x4, yang ditata dalam rancangan petak terbagi (split-plot design) yang diluluh dalam rancangan acak kelompok (RAK). Taraf faktor sayuran ditempatkan pada petak utama yaitu sayuran selada (S1), sayuran sawi (S2), sayuran campuran (S3), dan tanpa sayuran (S4). Kultivar umbi gladiol yaitu kultivar Holand Putih (VW) dan kultivar Holand Pink (VP) ditempatkan pada petak anak. Hasil penelitian menunjukkan bahwa: (1) Penanaman gladiol dengan sawi dan sayuran campuran (sawi dan selada) mempengaruhi jumlah daun gladiol secara nyata dengan rata-rata 8,54 dan 8,46 daun., (2) Kultivar Holland Pink menghasilkan variabel tinggi tanaman, jumlah daun, jumlah floret, diameter subang dan bobot subang yang lebih besar dibandingkan Holland Putih. Sedangkan untuk jumlah kormel, Holland Putih menghasilkan jumlah yang lebih banyak daripada Holland Pink, (3) Penanaman gladiol menggunakan sayuran sawi dengan kultivar Holland Pink menghasilkan panjang tangkai yang terbaik yaitu $98,38 \mathrm{~cm}$.
\end{abstract}

Kata Kunci : gladiol, sawi, selada, tumpangsari

\section{PENDAHULUAN}

Gladiol merupakan salah satu bunga potong yang memiliki nilai komersial cukup tinggi dan banyak diusahakan petani di dataran tinggi. Volume perdagangan bunga ini sekitar 127-200 tangkai per minggu. Keadaan ini sudah bisa ditingkatkan melalui teknik budidaya yang cepat. Usaha tani gladiol merupakan usaha komersial karena sebagian besar produksinya ditujukan untuk memenuhi kebutuhan pasar atau konsumen. Berdasarkan hal tersebut, pengkajian aspek Agro Ekonomi usaha tani gladiol mencakup kegiatan produksi, konsumsi dan pemasaran. Kebanyakan usaha tani gladiol dilakukan di daerah dataran tinggi sesudah tanaman sayuran, tanaman padi dan tanaman hias lainnya (Sutater, 1992).

Tumpangsari merupakan suatu usaha menanam beberapa jenis tanaman pada lahan dan waktu yang sama, yang diatur sedemikian rupa dalam barisan-barisan tanaman. Penanaman dengan cara ini bisa dilakukan pada dua atau lebih jenis tanaman yang relatif seumur, misalnya jagung dan kacang tanah atau bisa juga pada beberapa jenis tanaman yang umurnya berbeda-beda. Untuk dapat melaksanakan pola tanam tumpangsari secara baik perlu diperhatikan beberapa faktor lingkungan yang mempunyai pengaruh diantaranya ketersediaan air, kesuburan tanah, sinar matahari dan hama penyakit (Subhan, 1988). Menurut Effendi (1976), penggunaan tanaman sela dimaksudkan untuk meningkatkan pendapatan petani, menghindarkan kegagalan bagi satu jenis tanaman, dengan menambahkan satu atau lebih jenis tanaman lain yang mempunyai sifat yang kompatibel.

Gladiol memiliki tajuk yang tidak lebar sehingga dengan hal ini sinar matahari yang jatuh ke areal pertanaman akan banyak terbuang. Untuk mengantisipasi hal tersebut, maka penanaman secara tumpangsari sangat memungkinkan untuk dilakukan. Hal ini karena dengan adanya sistem tumpangsari pada pertanaman gladiol, maka sinar matahari yang jatuh ke areal pertanaman dapat dimanfaatkan untuk produksi.

Penerimaan cahaya matahari ini sangat bergantung pada tinggi dan lebar jenis tanaman yang ditumpangsarikan. Penerimaan cahaya matahari pada tanaman sangat penting karena akan berpengaruh pada hasil sintesa (glukosa) dan muara terakhir akan berpengaruh terhadap hasil poduksi tanaman secara keseluruhan (Budianto, 1988). 
Pada umur 1 bulan setelah tanam gladiol masih menggunakan umbi sebagai cadangan makanan. Pada umur tersebut gladiol tidak menyerap unsur hara yang ada di dalam tanah. Pada saat gladiol masih menggunakan umbi sebagai cadangan makanan maka dilakukan sistem tumpangsari dengan sayuran. Tanaman sayuran umumnya berproduksi pada umur 28-65 hari setelah tanam. Dengan penanaman sayuran di sekitar tanaman gladiol diharapkan sistem tumpangsari antar gladiol dan sayuran ini dapat berproduksi secara optimal. Hal ini dikarenakan pada penanaman gladiol yang memiliki tajuk yang tidak lebar, sehingga apabila ditanam tanaman dibawahnya maka intensitas sinar matahari yang dibutuhkan akan tercukupi.

Penelitian ini bertujuan untuk mengetahui pengaruh jenis tumpangsari pada pertumbuhan dan produksi dua kultivar gladiol, mengetahui respon masingmasing kultivar terhadap jenis tumpangsari, dan mengetahui jenis kombinasi tumpangsari yang berpengaruh terhadap masing-masing kultivar gladiol.

\section{BAHAN DAN METODE}

Penelitian ini dilaksanakan pada bulan Desember 2011 sampai dengan Mei 2012 di Jln. Swadaya VI kelurahan Gunung Terang, Kecamatan Tanjung Karang Barat Bandar Lampung.

Bahan yang digunakan bibit Gladiol kultivar Holand Pink dan Holand Putih, bibit Sawi, bibit selada, pupuk kandang, tanah, air, insektisida, fungisida. Alat yang akan digunakan pada penelitian ini yaitu: cangkul, bambu, sprayer, meteran, selang air, penggaris, jangka sorong, timbangan elektrik, gelas ukur, pinset dan sarung tangan karet.
Penelitian ini disusun menggunakan rancangan perlakuan faktorial $2 \times 4$, yang ditata dalam rancangan petak terbagi (split-plot design) yang diluluh dalam rancangan acak kelompok (RAK). Homogenitas ragam diuji dengan uji Bartlett sedangkan aditivitas ragam diuji dengan uji Tukey. Data pengamatan di analisis dengan analisis ragam dan dilanjutkan dengan uji Beda Nyata Terkecil (BNT) pada taraf 5\%.Taraf faktor sayuran ditempatkan pada petak utama yaitu sayuran selada (S1), sayuran sawi (S2), sayuran campuran (S3), dan tanpa sayuran (S4). Kultivar umbi gladiol yaitu kultivar Holand Putih (VW) dan kultivar Holand Pink (VP) ditempatkan pada petak anak.

Variabel yang diamati adalah jumlah daun, panjang daun, panjang tangkai, jumlah floret, diameter floret, diameter umbi, bobot umbi, jumlah kormel, bobot kormel, dan bobot kering brangkasan gladiol.

\section{HASIL DAN PEMBAHASAN}

Jenis tumpangsari sayuran sawi dan sayuran campuran menghasilkan rata-rata jumlah daun gladiol masing-masing 8,54 dan 8,46 helai yang tidak berbeda nyata dengan jumlah daun pada perlakuan sayuran selada dan tanpa sayuran yaitu masing-masing 8,13 dan 8,38 helai. Sedangkan untuk perlakuan jenis kultivar gladiol, kultivar Holland Pink menghasilkan rata-rata jumlah daun 8,48 helai yang berbeda nyata dengan kultivar Holland Putih dengan rata-rata jumlah daun 8,38 helai (Tabel 1 ).

Perlakuan kultivar Holland Pink menghasilkan rata-rata tinggi tanaman sebesar $103,44 \mathrm{~cm}$ yang berbeda nyata dengan kultivar Holland Putih sebesar $90,18 \mathrm{~cm}$. Perbedaan jenis kultivar gladiol pada jumlah

Tabel 1. Pengaruh jenis tumpangsari sayuran dan perbedaan kultivar terhadap jumlah daun

\begin{tabular}{lc}
\hline Perlakuan & Jumlah daun \\
\hline Selada & $8,13 \mathrm{a}$ \\
Sawi & $8,54 \mathrm{~b}$ \\
Campuran & $8,46 \mathrm{~b}$ \\
Tanpa sayuran & $8,38 \mathrm{ab}$ \\
\hline BNT 5\% & 0,25 \\
\hline Kultivar & Jumlah daun \\
\hline Kultivar Holland Putih & $8,27 \mathrm{a}$ \\
Kultivar Holland Pink & $8,48 \mathrm{~b}$ \\
\hline BNT 5\% & 0,18 \\
\hline
\end{tabular}

Keterangan: Nilai selajur yang diikuti oleh huruf yang sama tidak berbeda nyata menurut uji BNT $\alpha_{0,05}$. 
floret, kultivar Holland Pink menghasilkan rata-rata jumlah floret 9,54 kuntum yang berbeda nyata dengan kultivar Holland Putih dengan rata-rata jumlah floret 6,79 kuntum. Perbedaan jenis kultivar gladiol pada diameter subang, kultivar Holland Pink menghasilkan rata-rata diameter subang $5,30 \mathrm{~cm}$ yang berbeda nyata dengan kultivar Holland Putih dengan rata-rata diameter subang 4,48 cm (Tabel 2).

Pada hasil penelitian menunjukkan bahwa perlakuan jenis tumpangsari tidak berpengaruh terhadap tinggi tanaman gladiol. Perlakuan jenis kultivar memberikan pengaruh yang nyata terhadap panjang tangkai gladiol. Interaksi antara jenis tumpangsari dan jenis kultivar tidak berpengaruh nyata terhadap panjang tangkai. Untuk perlakuan kombinasi sayuran sawi dan Holland Pink menghasilkan rata-rata panjang tangkai sebesar 98,38 $\mathrm{cm}$ yang berbeda dengan perlakuan lainnya (Tabel 3).

Perlakuan jenis kultivar gladiol pada bobot subang, kultivar Holland Pink menghasilkan rata-rata bobot subang 37,78 yang berbeda nyata dengan kultivar Holland Putih dengan rata-rata bobot subang 27,72 gram. Perlakuan jenis kultivar gladiol pada jumlah kormel, kultivar Holland Pink menghasilkan rata-rata bobot subang 24,46 buah yang berbeda nyata dengan kultivar Holland Putih dengan rata-rata bobot subang 33,29 buah (Tabel 4).

Berikut ini merupakan hasil analisis tanah yang menunjukkan keadaan tanah pada masing-masing perlakuan. Analisis tanah dilakukan pada saat akhir dari penanaman gladiol. Nilai $\mathrm{N}$ total pada analisis tanah termasuk kategori tinggi karena nilai $\mathrm{N}$ pada tanah

Tabel 2. Pengaruh perbedaan kultivar terhadap tinggi tanaman, jumlah floret dan diameter subang

\begin{tabular}{cccc}
\hline \multicolumn{1}{c}{ Kultivar } & Tinggi tanaman $(\mathrm{cm})$ & Jumlah floret (kuntum) & Diameter subang (cm) \\
\hline Holland Putih & $90,18 \mathrm{a}$ & $2,70 \mathrm{a}$ & $4,48 \mathrm{a}$ \\
Holland Pink & $103,44 \mathrm{~b}$ & $3,16 \mathrm{~b}$ & $5,30 \mathrm{~b}$ \\
\hline BNT 5\% & 11,95 & 0,39 & 0,69 \\
\hline
\end{tabular}

Nilai selajur yang diikuti oleh huruf yang sama tidak berbeda nyata menurut uji BNT $\alpha_{0,05}$.

Tabel 3. Perbandingan panjang tangkai kultivar pada masing-masing jenis tumpangsari

\begin{tabular}{lcc}
\hline \multirow{2}{*}{ Tumpangsari } & \multicolumn{2}{c}{ Panjang tangkai kultivar gladiol (cm) } \\
\cline { 2 - 3 } & Holland Putih & Holland Pink \\
\hline Selada & $84,78 \mathrm{a}$ & $83,76 \mathrm{a}$ \\
Sawi & $84,73 \mathrm{a}$ & $85,66 \mathrm{a}$ \\
Campuran & $85,28 \mathrm{a}$ & $98,38 \mathrm{~b}$ \\
Tanpa sayuran & $92,32 \mathrm{~b}$ & $73,73 \mathrm{a}$ \\
\hline BNT5\% & & \\
\hline
\end{tabular}

Nilai dalam baris yang diikuti oleh huruf yang sama tidak berbeda nyata menurut uji $\operatorname{BNT} \alpha_{0,05}$.

Tabel 4. Pengaruh Perbedaan kultivar terhadap bobot subang dan jumlah kormel

\begin{tabular}{lcccc}
\hline \multirow{2}{*}{ Kultivar } & \multicolumn{2}{c}{ Bobot subang (gram) } & \multicolumn{2}{c}{ jumlah kormel (buah) } \\
\cline { 2 - 5 } & Data asli & Data transformasi & Data asli & Data transformasi \\
\hline Holland Putih & 27,72 & $5,22 \mathrm{a}$ & 33,29 & $1,72 \mathrm{~b}$ \\
Holland Pink & 37,78 & $6,15 \mathrm{~b}$ & 24,46 & $1,66 \mathrm{a}$ \\
\hline
\end{tabular}

$\begin{array}{lll}\text { BNT } 5 \% & 0,386 & 0,017\end{array}$

Nilai selajur yang diikuti oleh huruf yang sama tidak berbeda nyata menurut uji BNT $\alpha_{0,05}$. Data ditransformasi dengan transformasi akar $\mathrm{x}+0,5$ 
berkisar antara 0,1 sampai 0,75. Kadar P organik dalam bahan organik kurang lebih sama kadarnya dalam tanaman yaitu 0,2-0,5\%. Kadar unsur Kalium (K) dalam lahan penelitian gladiol masih cukup tinggi karena kadar normal yaitu 0,4-0,7 Me/100 g (Tabel 5).

Pada fase vegetatif kultivar Hollland Pink berbeda nyata dengan kultivar Holland Putih pada variabel tinggi tanaman dan jumlah daun. Namun pada variabel bobot kering brangkasan, Holland Pink tidak berbeda nyata dengan Holland Putih. Kulitvar Holland Pink memiliki rata-rata tinggi tanaman 103,44 cm sedangkan kultivar Holland Putih memiliki rata-rata 90,18 cm (Tabel 2). Pada jumlah daun, kultivar Holland Pink memiliki ratarata 8,48 daun sedangkan Holland Putih hanya memiliki rata-rata 8,27 daun (Tabel 1). Pada fase vegetatif umbi gladiol masih menunjukkan keadaan yang baik, sehingga pada fase ini tanaman gladiol masih memperoleh makanan yang ada pada subang tersebut. Pada fase vegetatif yaitu pada pembentukan akar dan daun, tanaman gladiol memanfaatkan cadangan makanan yang ada pada subang.

Pada fase generatif pada gladiol menunjukkan bahwa perbedaan kultivar gladiol berpengaruh yang nyata pada jumlah floret sedangkan pada panjang tangkai terdapat interaksi antara tumpangsari sayuran dan gladiol dan pada diameter floret tidak menunjukkan perbedaan yang nyata. Pada jumlah floret, kultivar Holland Pink memiliki jumlah floret yang lebih tinggi dibandingkan Holland Putih. Kultivar Holland Pink memiliki rata-rata jumlah floret yaitu 9,54 floret dan Holland Putih hanya memilki rata-rata jumlah floret yaitu 6,79 floret (Tabel 2). Hal ini dikarenakan karena adanya persaingan antara sayuran yang ditumpangsarikan dengan gladiol. Dengan adanya persaingan tersebut maka mempengaruhi jumlah floret bunga gladiol. Dua jenis tanaman yang ditanam dengan jarak tanam kurang dari $100 \mathrm{~cm}$ akan terjadi persaingan antar keduanya (Warsana. 2009).

Panjang tangkai pada perlakuan ini berbeda nyata dengan perlakuan lainnya tetapi tidak berbeda nyata dengan perlakuan tanpa sayuran pada Holland Putih dengan rata-rata 92,32 cm (Tabel 3). Herlina (1991) menyatakan bahwa pertumbuhan dari masing masing kultivar mempengaruhi bentuk floret, panjang tangkai bunga, diameter floret apabila penggunaan ukuran subang bibit yang berbeda serta kesuburan pada tanaman berbeda.

Pada variabel produksi, perbedaan kultivar gladiol menunjukkan perbedaan yang nyata pada variabel diameter subang, bobot subang dan jumlah kormel. Akan tetapi perbedaan kultivar tidak memberikan perbedaan yang nyata terhadap bobot kormel. Perbedaan ini karena karakteristik antara Holland Pink dan Holland Putih yang berbeda. Selain itu juga, perbedaan bobot pada saat penanaman gladiol menghasilkan perbedaan kultivar yang nyata pada beberapa variabel produksi Menurut Indrastuti et al. (2010), semakin besar ukuran subang berarti cadangan makanan untuk mendukung pertumbuhan juga semakin besar. Bobot subang berpengaruh pada pertumbuhan tanaman gladiol selanjutnya, karena ditentukan oleh jumlah makanan yang berasal dari subang (Soedarjo dan Wuryaningsih, 2010).

Meskipun Holland Putih memiliki jumlah kormel yang lebih banyak daripada Holland Pink tetapi keduanya memiliki bobot bormel yang tidak berbeda nyata. Hal ini karena ukuran kormel yang dimiliki Holland Putih lebih kecil daripada Holland Pink. Akan tetapi Holland Putih memiliki jumlah kormel yang lebih banyak daripada Holland Pink. Semakin besar ukuran kormel yang digunakan sebagai bibit akan meningkatkan jumlah floret dan bobot kormel (Andalasari, 2005).

Pada semua variabel pengamatan, perlakuan jenis tumpangsari tidak menunjukkan perbedaan yang nyata baik pada fase vegetatif, generatif dan produksi. Hal ini dikarenakan suplai hara terhadap kedua jenis tanaman tercukupi baik pada fase vegetatif, generatif dan produksi. Selain itu, kebutuhan sinar matahari bagi kedua jenis tanaman juga tercukupi. Hal ini karena tajuk dari gladiol yang tidak lebar baik pada saat fase awal penanaman hingga panen tidak menutupi atau menaungi tanaman sayuran yang ditumpangsarikan sehingga

Tabel 5. Hasil analisis tanah pada akhir penelitian

\begin{tabular}{lrrrr}
\hline \multicolumn{1}{c}{ Jenis uji } & Selada & Sawi & Campuran & Tanpa sayuran \\
\hline $\mathrm{pH} \mathrm{H} \mathrm{H}_{2} \mathrm{O}$ & 5,60 & 5,60 & 5,60 & 5,60 \\
N-tot $(\%)$ & 1,37 & 1,42 & 1,48 & 1,40 \\
C-organik & 0,83 & 0,87 & 0,87 & 0,83 \\
P-ter (ppm) & 7,05 & 7,23 & 7,56 & 7,11 \\
K-dd ( me/100 g) & 0,58 & 1,02 & 1,02 & 0,56 \\
\hline
\end{tabular}

Sumber : Laboratorium Analisis Tanah Polinela (2012) 
kebutuhan sinar matahari bagi kedua tanaman tersebut tercukupi.

\section{KESIMPULAN}

Berdasarkan penelitian yang telah dilakukan dapat disimpulkan bahwa penanaman gladiol dengan tumpangsari jenis sayuran tidak mempengaruhi variabelvariabel pada fase vegetatif, generatif dan produksi. Kultivar Holland Pink menghasilkan variabel tinggi tanaman, jumlah daun, jumlah floret, diameter subang dan bobot subang yang lebih besar dibandingkan Holland Putih. Sedangkan untuk jumlah kormel, Holland Putih menghasilkan jumlah yang lebih banyak daripada Holland Pink. Penanaman gladiol menggunakan sayuran sawi dengan kultivar Holland Pink menghasilkan panjang tangkai yang terbaik yaitu $98,38 \mathrm{~cm}$.

\section{UCAPAN TERIMA KASIH}

Ucapan terima kasih disampaikan kepada Ir. Kushendarto, M.S yang telah memberikan saran dan membimbing penulis dalam penelitian ini.

\section{DAFTAR PUSTAKA}

Andalasari, T.A. 2005. Pengaruh Ukuran Umbi Pada Pertumbuhabdan Produksi Dua Varietas Gladiol. Menuju Produk Hortikultura Indonesia Berkualitas. Departemen Agronomi dan Hortikultura. Faperta IPB.Bogor. J-Hort. HIm 257 -264 .
Budianto.1988. Pengaruh Jarak Tanam Pada Tanaman Kacang Tanah yang Ditumpangsarikan dengan Jagung. Skripsi. Universitas Gajah Mada 2011

Effendi, S.S. 1976. Pola bertanam. LP3 Bogor. 49 hlm Herlina, D. 1991. Gladiol. Penebar Swadaya. Jakarta. $18 \mathrm{hlm}$.

Indrastuti, Rahmawati dan . 2010. Respon TunasGladiol Hasil Subkultur. Faperta Universitas Negeri Malang. Prosiding Hortikultura. 13 (2):16-18

Soedarjo. M dan Wuryaningsih. 2010. Respon Beberapa Varietas Nasional Gladiol Terhadap Pemupukan $N$ dan $K$. Balai Penelitian Tanaman Hias. J-Hort. XX ( II):194 hlm.

Sutater, T. 1992. Pengaruh Pembelahan SubangdanTumpangsari Terhadap Pertumbuhan dan Produksi Bunga Gladiol Kultivar Queen Occer. Laporan Penelitian Sub Balihort Cipanas

Subhan, 1988. Pengaruh tumpangsari jagung dan kentang terhadap pertumbuhan dan hasil pada musim kemarau. Bul. Penel. Hort.16(3):58 - 62.

Warsana. 2009. Introduksi teknologi Tumpangsari Jagung dan Kentang.Bul. Penel. 45(7):9-12 